Below we are publishing a commentary by Professor Stanton Glantz, in which he lays out his views on the appropriate role of the National Cancer Institute (NCI) in supporting tobacco control research. The National Cancer Institute is part of the National Institutes of Health, which is the lead federal agency $\vec{\Rightarrow}$ funding biomedical research in the United States. Following Glantz's commentary, we publish five replieso from seven others involved in tobacco control research and practice.

This discussion is particularly timely for two reasons. First, it takes place as the NCI is winding down $\frac{\overline{\bar{c}}}{\overrightarrow{1}}$. a large demonstration in tobacco control: the American Stop Smoking Intervention Study (ASSIST). $\mathbb{\mathbb { Q }}_{\square}$ ASSIST followed the NCI's first large-scale community study in tobacco control: the Community Inter-@ vention Trial for Smoking Cessation (COMMIT). Second, publication of this issue of Tobacco Control ${ }_{\vec{O}}$ coincides with publication of a special supplement to the journal, which is devoted to research related to... COMMIT and ASSIST.

We invite readers to share their own views with us in the form of letters to the editor. Instructions for let-o ters to the editor appear in our Instructions to Authors, which were published in our Spring 1997 issue and $\vec{\rho}$ which are available on our web site $<$ http://www.tobaccocontrol.com $>.,-E D$

\title{
After ASSIST, what next? SCIENCE
}

While the US Food and Drug Administration's (FDA's) efforts to regulate tobacco products and the deal made by the attorneys general with the tobacco industry to "settle" their suits over smoking-induced disease have dominated the headlines in the United States, the federal government's most successful effort to curb tobacco has been the National Cancer Institute's (NCI's) American Stop Smoking Intervention Study (ASSIST). ASSIST, a state-based programme built around local coalitions and media advocacy, has reduced per capita consumption of cigarettes by $7 \%$ compared with non-ASSIST states. ${ }^{12}$ This seemingly modest change amounts to about 50 million packs of cigarettes a month not being smoked. Indeed, the ASSIST "market share" now exceeds that of all other brands of cigarettes except Marlboro $^{3}$ (table). This represents a stunning accomplishment for the public health, particularly in light of efforts by the tobacco industry to cripple ASSIST.

Given this success, it is remarkable that the NCI has no approved plan for a follow-on trial to build on ASSIST's success. Instead, the current plan is to simply transfer the programme to the US Centers for Disease Control and Prevention's (CDC's) Office on Smoking and

Market share of different brands of cigarettes, $1996^{2}$

\begin{tabular}{lcl}
\hline Brand & $\begin{array}{c}\text { Market share } \\
(\%)\end{array}$ & Company \\
\hline Marlboro & 32.3 & Philip Morris \\
ASSIST & 7.0 & National Cancer Institute \\
Newport & 6.1 & Lorillard \\
Doral & 5.9 & RJ Reynolds \\
GPC & 5.8 & Brown \& Williamson \\
Winston & 5.3 & RJ Reynolds \\
Basic & 4.8 & Philip Morris \\
Camel & 4.6 & RJ Reynolds \\
Kool & 3.6 & Brown \& Williamson \\
Salem & 3.6 & RJ Reynolds \\
Virginia Slims & 2.4 & Philip Morris \\
Merit & 2.3 & Philip Morris \\
Benson \& Hedges & 2.3 & Philip Morris \\
\end{tabular}

*ASSIST is not a brand of cigarettes, but by reducing consumption by $7 \%$, it has the same effect on the other cigarette brands as if it were a brand attracting new customers.
Health. It would appear that NCI plans to abandon large-scale, population-based inter- vention studies and return to bench and 8 behavioural research and small-scale, investigator-initiated projects. Although thereo is no question that such small-scale projects are important and worthy of NCI support, it is simply unacceptable for NCI to abandon this most promising line of research and development in tobacco control.

While CDC should expand its state efforts based on the ASSIST model (including much larger funding levels for individual states than CDC currently provides), expansion of CDC음 efforts does not obviate the need for NCI to develop and evaluate the next generation of large-scale tobacco control interventions. Afterô all, the NCI's primary function is the development of new knowledge and the CDC'sfunction is promotion of strong public health 3 practice once it has been developed. Failing to recognise this distinction by coupling the issues of the future of large-scale tobacco controlo research at NCI and expansion of the CDC's state-based tobacco control programme, IMPACT, has confused the question of what the new research agenda should be. The issues. of NCI's future research agenda for large-scale $N$ tobacco control interventions and the CDC's $N$ future expansion are fundamentally different ${ }^{\sigma}$ questions which need to be addressedo independently.

New research and development work on large-scale tobacco control is all the more $\frac{0}{0}$ important because a growing number of statesत् have funded multi-million dollar tobacco con- $\frac{\stackrel{?}{6}}{\mathrm{O}}$ trol programmes as well as the possibility that national policy making may lead to more resources being devoted to tobacco control.o The ASSIST programme is scheduled to end in 1999, so it is long past the time that the NCKo을 should have started planning the follow-on ${ }^{\circ}$ research and development programme to continue to improve the effectiveness of population-based tobacco control interventions. 
The rate of tobacco use is not identical in all states. States that have made investments in comprehensive tobacco prevention and control programmes have consistently out-performed other states in reducing tobacco use. The state of California implemented a large-scale comprehensive programme beginning in 1989 and saw a tripling in the rate of decline of tobacco consumption. ${ }^{56}$ There were major reductions in adult smoking rates, and no increases in teenage smoking rates (until the programme was narrowly focused on young people, when adult smoking stopped dropping and teenage smoking increased. ${ }^{7}$ ) Massachusetts implemented a similar programme two years later and since then Arizona and Oregon have followed suit. ASSIST was the model for the development of these state-based tobacco control interventions as well as the model for the CDC's IMPACT programmes and the Robert Wood Johnson Foundation's SmokeLess States programme.

The field of tobacco control is undergoing fundamental change. Litigation by states and other groups may change the way tobacco is advertised and sold. ${ }^{8}$ Maine (through a doubling of the state's cigarette excise tax) and Wisconsin (through the normal budgeting process) are also beginning state-funded tobacco control programmes. Florida and Mississippi have obtained millions of dollars for tobacco control programmes as part of their state settlements with the tobacco companies. The number of states receiving such funds will increase. The discussions about a national deal with the tobacco industry may generate a large pool of federal funds for tobacco control, and this may occur even if a deal is not enacted because public health groups demand adequate funding. The death toll of tobacco clearly justifies greater government resources. ${ }^{9}$ These developments highlight the importance of continuing research and development designed to improve the effectiveness of largescale tobacco control interventions.

The promising results of the current ASSIST programme indicate that these programmes can be effective, and they challenge NCI to develop a follow-on programme that will be even more effective in reducing tobacco consumption and the associated cancer and heart disease toll. Although the effectiveness of state tobacco control programmes has been demonstrated, fundamental research questions about these programmes remain unanswered. It is clear, however, that such large-scale media and population-based tobacco control programmes are the most promising approach to reducing the toll of tobacco.

As ASSIST draws to an end, it is imperative that NCI implement a new population-based research programme involving $15-20$ states to develop and study the impact of innovative tobacco prevention and control interventions at the community, state, and multi-state level. Such a programme might be called SCIENCE-Smoking Control Innovation and Evaluation in New Community Environments. This research programme should build on the success of ASSIST and should simultaneously provide resources to research institutions and state and local tobacco control coalitions to undertake multiple studies collaboratively. All states should include a paid counteradvertising campaign as one of their interventions. Policy interventions at the state and local levels should also be required. This programme should be new, including an open competition with awardees selected through peer review, not simply a continuation of the existing ASSIST programme. The results of this research will provide knowledge that can be used to improve tobacco control programmes in the remaining states and throughout the world.

ASSIST has taught us about the value of public policy interventions to reduce tobacco use. In contrast to its predecessor, NCI's Community Intervention Trial for Smoking Cessation (COMMIT), which expressly prohibited public policy activity, ASSIST stressed it. Policy interventions designed to change the environment (ASSIST) work better than education (COMMIT). SCIENCE should be designed with this lesson in mind.

SCIENCE should begin the day after ASSIST ends. Many different aspects of the interventions are appropriate subjects of research. The following are examples of broad research questions that might be addressed through this project.

- In the context of a state-wide programme, what is the impact of a large counteradvertising campaign on attitudes toward tobacco advertising, tobacco use, and the tobacco industry?

- What themes of counter-advertising campaigns are most effective in achieving the goals of the campaign?

- How do state laws that preempt local tobacco control legislation influence the public's knowledge, attitudes, and behaviour related to tobacco?

- How should tobacco control programmes be modified to be most effective in tobaccogrowing states?

- How should tobacco control programmes be modified to meet the needs of special population groups?

- How can new funds be used to reduce tobacco use as rapidly as possible?

- What is the optimum level of per capita spending on tobacco control programmes?

- Which public policies are most strongly predictive of reductions in tobacco use?

- How will the tobacco industry respond and what are the best strategies for countering their response?

- What are the most appropriate methods for researching a rapidly changing field such as tobacco control, when traditional randomised trials are no longer possible?

NCI should seek to coordinate these large-scale research activities with CDC's IMPACT programmes to ensure the most efficient technology transfer and the most effective use of CDC's epidemiological surveillance capabilities. Moreover, the existence of different levels of tobacco control programmes 
(CDC IMPACT states funded at current ASSIST levels of at least $\$ 1$ million per state, SCIENCE states with significant programmes in addition to IMPACT, and the states with very large tobacco control programmes such as California and Massachusetts) will provide an opportunity to study the "dose-response" relationships for tobacco control programmes.

This SCIENCE proposal simply represents a logical follow-up to the demonstrated success of ASSIST. If the NCI conducted a clinical trial of a breast cancer treatment that reduced mortality by $7 \%$, it would immediately begin a follow up designed to test better treatments. Tobacco should be treated no differently. Lung cancer is the leading cause of cancer deaths and tobacco causes almost all lung cancer.

It is important that researchers recognise that tobacco control has become sufficiently high profile and dynamic that traditional randomised controlled-trial models probably will not be applicable. It is more likely that research models based on econometrics, political science, law, and epidemiological surveillance will be most appropriate. In the special supplement to this issue of Tobacco Control, NCI director Richard Klausner acknowledges the success of ASSIST and the need for new forms of evaluation for such programmes beyond the traditional randomised clinical trial. ${ }^{10}$ This recognition makes the NCI's abandonment of such research all the more remarkable.

Development of the SCIENCE populationbased programme is not the only area in which NCI needs to strengthen its activities related to tobacco control. Despite the fact that tobacco accounts for about $30 \%$ of all cancer deaths, ${ }^{11}$ $\mathrm{NCI}$, by its own accounting, spends less than $3 \%$ of its $\$ 2.3$ billion budget ${ }^{12}$ on tobacco research (including ASSIST and tobaccorelated biomedical research); these numbers are clearly out of balance. Less than $1 \%$ of NCI's budget goes to investigator-initiated research grants related to tobacco control (and NCI is doing better than the rest of the National Institutes of Health).

NCI must also increase funding for a broad range of tobacco control research and see that appropriate mechanisms for peer review of grant applications are put in place. ${ }^{13}$ Several years ago NCI issued a request for proposals on policy research and ended up funding several important projects, and it recently solicited and funded grants related to young people and smoking. These actions were good first steps that demonstrated a pool of good ideas worthy of funding. It is time for NCI to initiate a large, broad-based programme of investigator-initiated tobacco control grants. Such a programme can only complement SCIENCE.

The NCI cannot be allowed to walk away from its responsibility to continue developing and evaluating large-scale tobacco control interventions as well as putting in place a substantial programme of investigator-initiated grants that deal with tobacco control. It is up to the public health community to see that the $\mathrm{NCI}$ and the Clinton Administration go the next step.

STANTON A GLANTZ 을

University of California,

San Francisco, California 94143, USA;

email: glantz@cardio.ucsf.edu

1 Manley M, Lynn W, Epps R, Grande D, Glynn T, Shopland D. The American Stop Smoking Intervention study for cancer prevention: an overview. Tobacco Control 1997; 6(suppl 2):S5-11.

2 Manley M, Pierce J, Gilpin E, Rosbrook B, Berry C, Wun L-M. Impact of the American Stop Smoking Intervention Study (ASSIST) on cigarette consumption. Tobacco Control 1997;6(suppl 2):S12-16.

3 Maxwell J. Market up: Philip Morris and Lorillard report 1996 growth in US cigarette market. Tobacco Reporter 1997:23-5.

4 Mintz J. 17-state federal programme cuts smoking, draws fire. Washington Post 1997 Apr 19:A1

5 Glantz S. Changes in cigarette consumption, prices, and tobacco industry revenues associated with California's Proposition 99. Tobacco Control 1993;2:311-14.

6 Glantz S. Alternative models for controlling smoking among adolescents: Glantz responds. Am f Public Health 1997; 87:870-1

7 Tobacco Education and Research Oversight Committee. Toward a tobacco-free California: renewing the commitment 1997-2000. Sacramento, California: Tobacco Education and Research Oversight Committee, 31 July 1997.

8 Glantz SA, Fox BJ, Lightwood JM. Tobacco litigation. Issues for public health and public policy. $¥ A M A$ 1997;277:751-3.

9 Glantz S. Actual causes of death in the United State (letter). $\mathcal{F} A M A$ 1994;271:660.

10 KIausner R. Evolution of tobacco control studies at the National Cancer Institute. Tobacco Control 1997;6(suppl 2):S1-2.

11 National Cancer Institute. Cancer risks and rates. Bethesda, Maryland: National Institutes of Health, 1996:96-691.

12 National Cancer Institute. The nation's investment in cancer research: a budget proposal for fiscal year 1999. Bethesda, Maryland: NCI, 1997.

13 Glantz SA, Bero LA. Inappropriate and appropriate selection of 'peers' in grant review. $\mathcal{F} A M A 1994 ; 272: 114-6$. 